\title{
Investigation on the effect of phase segregation on the mechanical properties of polymer modified bitumen using analytical and morphological tools
}

\author{
Noor Zainab Habib ${ }^{1, *}$, Ibrahim Kamaruddin ${ }^{2}$, Isa $M$ Tan $^{2}$ and Masaharu Komiyama ${ }^{3}$ \\ ${ }^{1}$ Heriot-Watt University Dubai Campus, Dubai International Academic City, Dubai, U.A.E \\ ${ }^{2}$ Universiti Teknologi PETRONAS, Bandar Sri Iskandar, Tronoh, Perak, Malaysia \\ ${ }^{3}$ University of Yamanashi, Japan Chome-3-11 Takeda, Kofu, Yamanashi Prefecture 400-8510, Japan
}

\begin{abstract}
The mechanical strength of polymer modified bituminous mix which is evaluated in terms of stiffness reflects the deformation behaviour of bituminous mixture. The stiffness of the binder strongly depends on its chemical composition besides aggregate structure of the bituminous mixture. Compatibility of polymer with the base bitumen is considered as major strength enhancing factor in the case of polymer modified bituminous mix. To relate the factors affecting the mechanical strength of the binder a new approach in this research study was adopted in order to relate the compatibility of $80 / 100$ pen bitumen with polymer Polypropylene (PP) using analytical and morphological tools. Morphological tools like Atomic Force Microscopy (AFM) and Transmission Electron Microscope (TEM) were used to study the changes due to the difference in compatibility of polymer with bitumen. It was observed that the presence of phase segregated layer as observed by AFM surface morphology was considered as the main strength enhancing factor of the bituminous mix. While the presence of lamella as observed in TEM scanned images of PP PMB revealed that addition of polymer forms localized network in the phase segregated layer which induces the stiffening effect in PMB. From the chromatographic method (SARA) analytical analysis Saturate, Aromatics, Resin and Asphaltene fractionate were determined in the blend. It was observed that chemical composition of the blend also has a profound effect on the rheological properties and on the morphology of polymer modified bituminous (PMB) blend. It was concluded that PP PMB gets benefited by phase segregated layer in the blend when the polymer concentration was kept below $3 \%$ as it sufficiently enhances the mechanical strength of the PMB binder as observed by dynamic creep results.
\end{abstract}

*Corresponding author : $\underline{\text { n.habib@hw.ac.uk }}$ 


\section{Introduction}

Bitumen modification with polymer has now become the most widely used alternate method to improve the pavement performance properties. Polymer modified bituminous binder (PMB) are used because of its better engineering properties which are considered as a major element in extending the service life of the pavement. Enhanced engineering properties due to PMB modification were observed in terms of reduction in pavement deterioration by improvement in high temperature rutting resistance, reduction in low temperature thermal cracking and reduction in fatigue crack propagation [1].

In order to get the best results, compatibility of the blend is considered an important issue as it has a strong influence on its morphology and rheology, as low molecular weight bitumen when mixed with high molecular weight polymer compatibility, is difficult to achieve as it depends on the solubility parameters of bituminous blend [2]. Thermoplastic polymers because of their higher viscosity at high temperature and lower density than bitumen usually tends to cream. The blend thus produced doesn't have any chemical interaction and should be treated only as a physical system consisting of two partially miscible phases [3].

Oxidation of bitumen during blending or in-service life of pavement also considered as one of the major cause of stiffening or strength affecting factor of the binder. Thus the study of the chemical composition in understanding and effect of modification on the chemical fractions present before and after modification is important to know [4]. The evolution of chemical structure because of modification usually enhances the mechanical strength of binder and ultimately the modified bituminous mix [5]. Since polymer and bitumen are two immiscible component of the blend because of their difference in molecular weight [6], this difference has a profound effect on the physical, chemical and mechanical properties of the PMB blend. The characteristics of the mix were due to thermodynamic instability as for thermodynamically stable blend the Gibbs free energy of the mix must be lower than zero [7].

\section{Objective of study}

This objective of this study was to discuss the behaviour of polymer Polypropylene used as a modifier for $80 / 100$ pen bitumen with its effect on rheology and morphology. The morphological study is considered incomplete and thus supplemented with the chemical analysis using SARA fractionate analysis which provides the information about the change in the content of saturate, aromatics, resins and asphaltene in the blend. The unique behaviour of polymer in the blend as revealed by the morphological and chemical analysis helps in understanding the thermodynamics of partially dispersed polymer and to understand the effect of polymer bitumen incompatibility on mechanical strength. The mechanical strength will be evaluated by Dynamic creep test results.

\section{Methodology}

\subsection{Material}

The material used includes, 80/100 penetration grade base bitumen obtained from PETRONAS refinery, Melaka, Malaysia and Polypropylene (PP) in the powder form was used for modification supplied by PETRONAS Polypropylene Sdn. Bhd. Malaysia. The polymer has melt flow index of $8 \mathrm{~g} / 10 \mathrm{~min}$ and density of $0.887 \mathrm{~g} / \mathrm{cm}^{3}$.

\subsection{Sample preparation and test methods used for analysis}


PP modified blend was prepared by mixing 80/100 Pen bitumen with polypropylene at 120 $\mathrm{rpm}$. Slow rate of mixing was adopted intentionally as it was known that compatibility of polymer can't be achieved. Thus only for physical dispersion of polymer in bitumen, slow speed was adopted and also to prevent the agglomeration. The concentration of PP was kept between $1-3 \%$ by weight of bitumen. Morphological analysis was done to study the evolution of structure brought by chemical changes in the virgin bitumen after modification using atomic force microscopy (AFM) using SII NANO NAVI E- Sweep and transmission electron microscopy (TEM) by using ZEISS LIBRA 200 FE.

Chemical analysis for the determination of asphaltene was done according to ASTM D3279 while SARA chromatographic method ASTM D 4124 - 01 was used to fractionate bitumen. For mechanical analysis of bituminous mix, Dynamic Creep test was performed according to BS D 226. The creep deformation of Standard Marshall Specimens prepared at optimum bitumen content for virgin and PP modified mix was measured as a function of pulse counts or rather time. The load used during the test on the specimens was uniaxial and dynamic, representing the repeated application of axle loads on the pavement structure. The results obtained were used to develop the relationship between mixture stiffness to the binder stiffness to predict mechanical performance of mix.

\section{Results \& discussion}

\subsection{Morphological analysis}

AFM and TEM were used to study the internal morphology of the PMB. The analysed samples describe the extent of the continuous phase in the blend and compatibility of the bitumen-polymer within the blend. The compatibility of the bitumen with the polymer depends on molecular weight, as higher molecular weight polymers are incompatible with lower molecular weight bitumen [6].

AFM images were taken in tapping mode, which revealed information in three dimensional topography and phase shift, as shown in the images of virgin and modified bitumen in Figure 1-5. Different surface compositions were observed in phase shift contrast. Figure1(a) shows a two - dimensional phase image of virgin bitumen in which "bee" structure can be observed, which was believed to be asphaltene micelles $[6,8]$. The three - dimensional phase image of the same bee structure is shown in Fig.1(b), in which protruding tubers from the surface of maltene fraction can be observed representing asphaltene $[6,9]$, most polar fraction of the bitumen while the surrounding phase around bee structure formed by lighter or less polar fraction maltene composed mainly of resin and aromatics. The surrounding flat surface may be concluded as non-polar saturates or alkanes. Within this protruding structure two different phases can be observed with altering dark and bright region [10]. These alternating light and dark regions in bee represents portion of different relative stiffness (different viscoelastic properties) having contrasting mechanical properties. The same protrudes having different viscoelastic properties were observed in Figure 2, in TEM image of virgin bitumen which under prolong exposure of electron beam disappears after some time. Figure 3(a) -5(a) shows the evolution of phase change with the addition of PP in bitumen. Phase evolution was observed with the formation of phase separated polymer layer on the surface of bitumen whose thickness seems to be increasing with concentration of polymer in blend as higher molecular weight polymer seems to be incompatible with the lower molecular weight bitumen thus causing the phase separation [6]. The TEM images of the same samples shows fine streaks of lamella, which was supposed to be due to presence of isotactic polypropylene in the PMB blend. The 3D AFM phase images of PP modified bitumen shows variation in surface roughness which decreases with the increase in polymer concentration in 
the blend. From Figure 3 (a), 1\%PP PMB phase image shows phase separated polymer layer totally covering the underneath bitumen layer, as evidenced by the disappearance of the "bee" structures. It is noted in Figure 3(a) that the phase image of 1\% PP PMB is very rough, indicating that the surface is micro-mixture of two materials having different viscoelastic properties. TEM scanned image of same sample (Figure 3(b), 4(b) \& 5(b) shows helical entangled chain of PP where dispersion and thickness of entangled chain decreases with the increase in polymer content indicating that higher polymer content in bitumen brings segregation of polymer and bitumen. The fine streaks of polymer totally covers the underneath bitumen layer. This interpretation was also confirmed by AFM scanned images (Figure 3(a), 4(a) \& 5(a) where PP segregated layer clearly visible forming a surface that is a micro-mixture of bitumen and PP. Figure 4(a) of 2\% PP PMB although shows surface roughness, but to much less degree compared to $1 \% \mathrm{PP}$ PMB, indicating that the cover- up of the surface by segregated PP is more complete when PP concentration is increased to $2 \%$. $3 \%$ PP PMB as shown Figure 5 (a) where phase image expose a complete flat phase separated layer of polymer above the bitumen. These AFM images unfold the surface evolution by the segregated PP.

The morphological phase segregation in the PP PMB blend as observed by AFM images were due to thermodynamic instability in the blend as the weak van der Wall forces in the blend were just attractive forces unable to generate heat increasing enthalpy of the blend, while the high molecular weight polymer at higher concentration level tends to agglomerate due to presence of dispersed polymer particles increasing the molar volume and decreasing the entropy of the blend which ultimately leads to phase segregation due to the instability of blend on cooling [7].

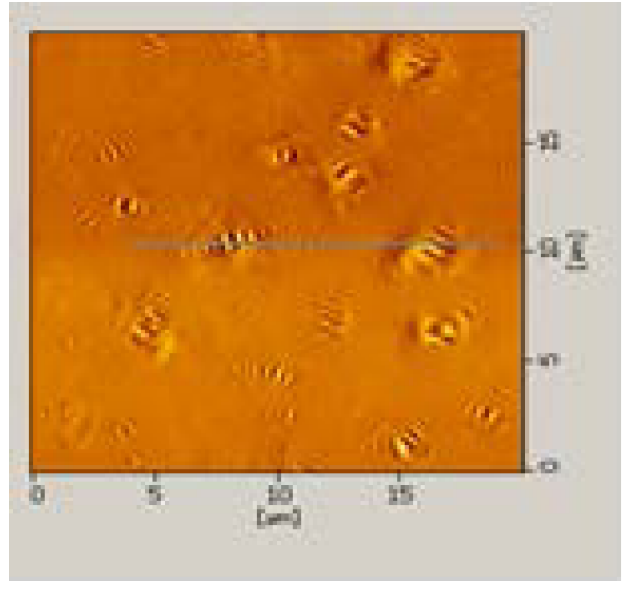

(a)

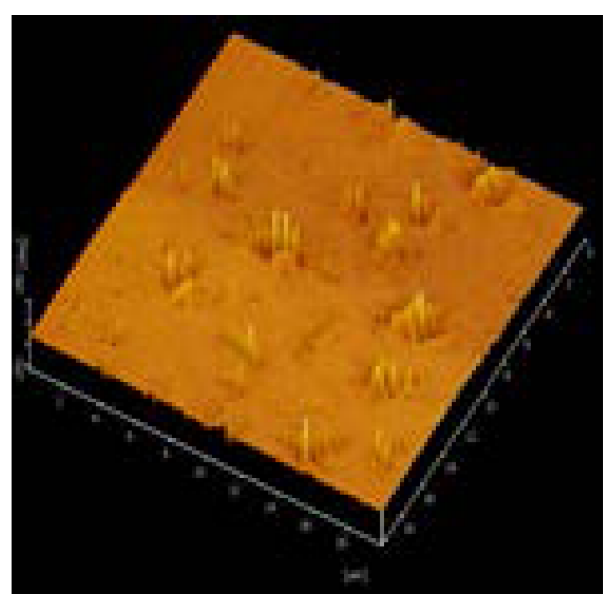

(b)

Fig. 1. Virgin Bitumen AFM images (a) Phase image (b) 3 D image. 


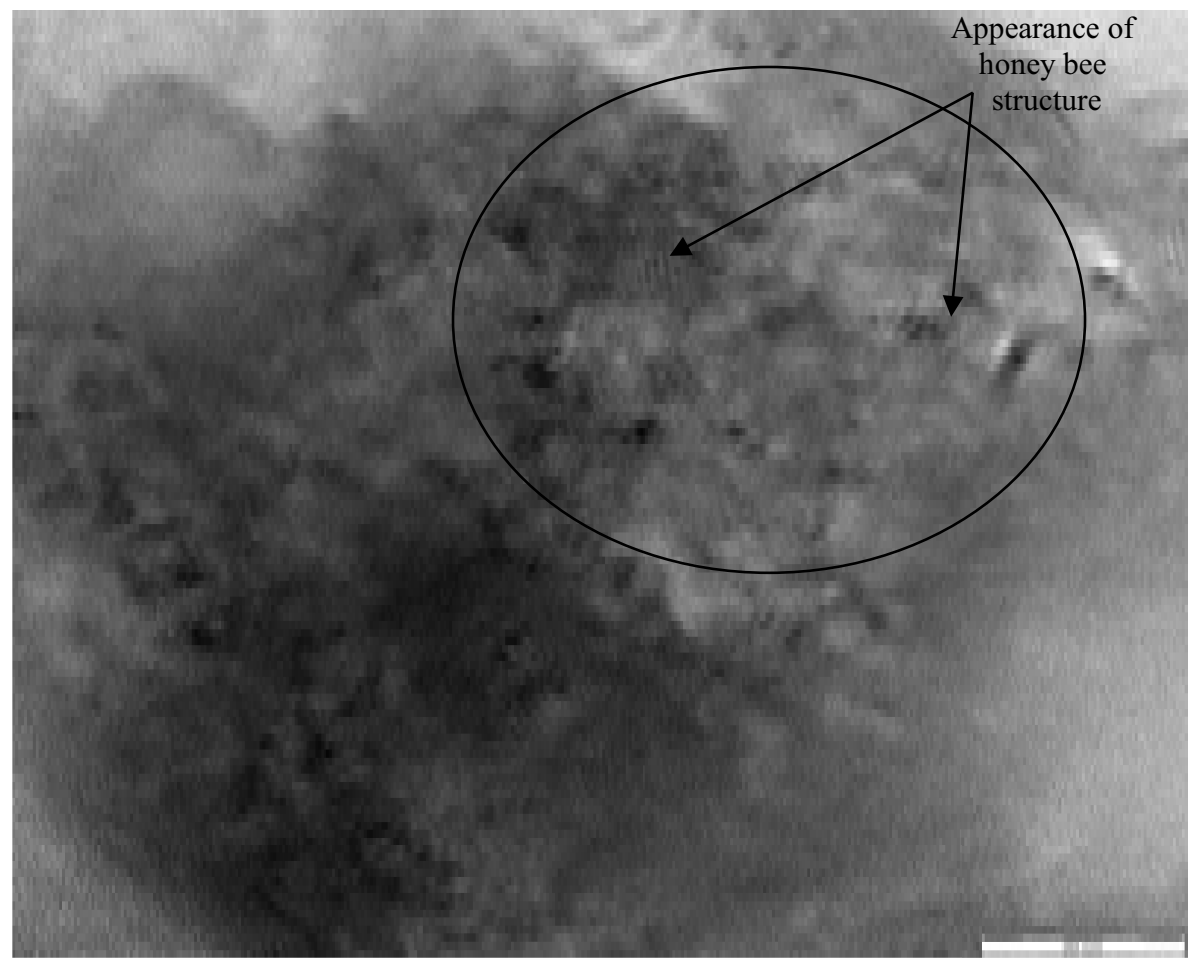

Fig. 2. TEM image of Virgin Bitumen.

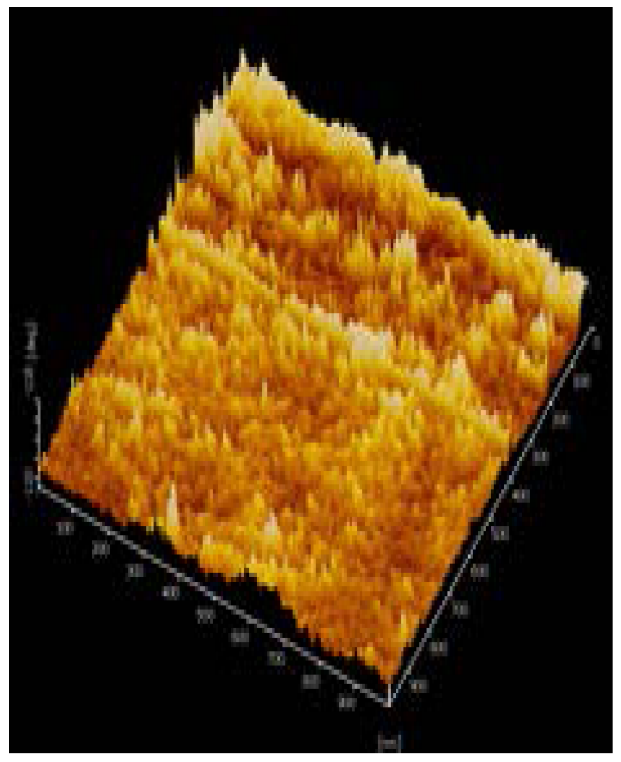

(a)

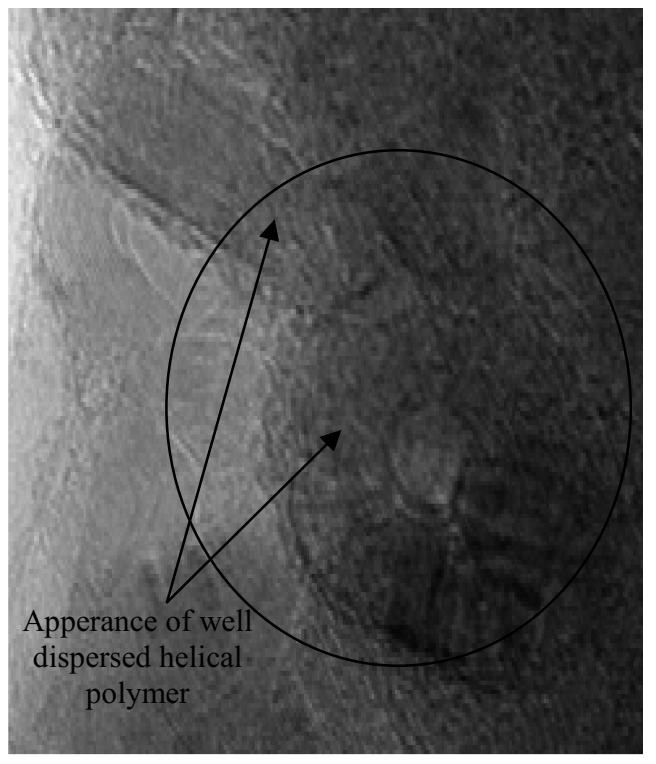

(b)

Fig. 3. $1 \%$ PP PMB (a) AFM image (b) TEM image. 


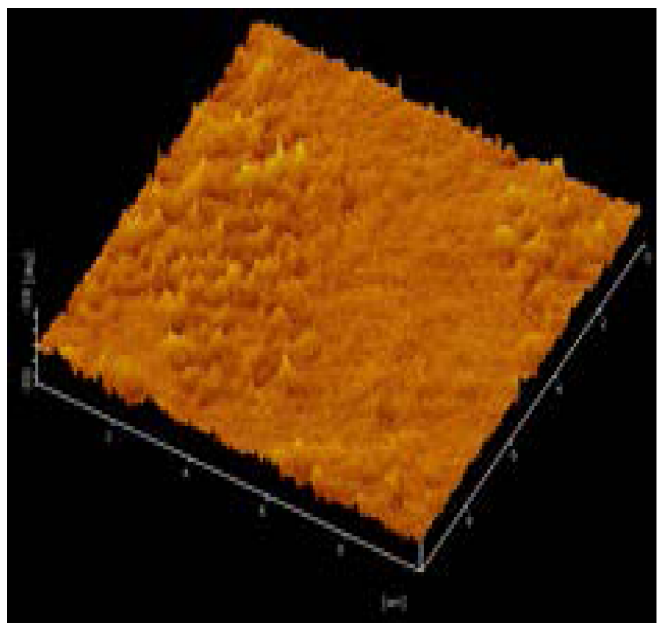

(a)

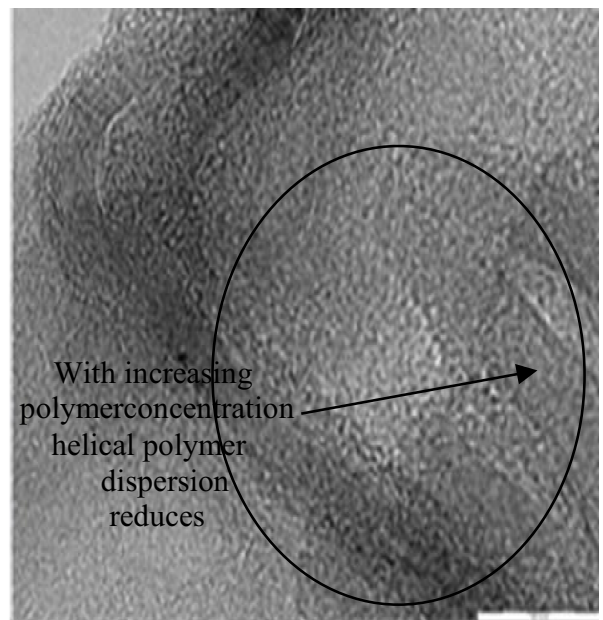

(b)

Fig. 4. 2\% PP PMB (a) AFM image (b) TEM image.

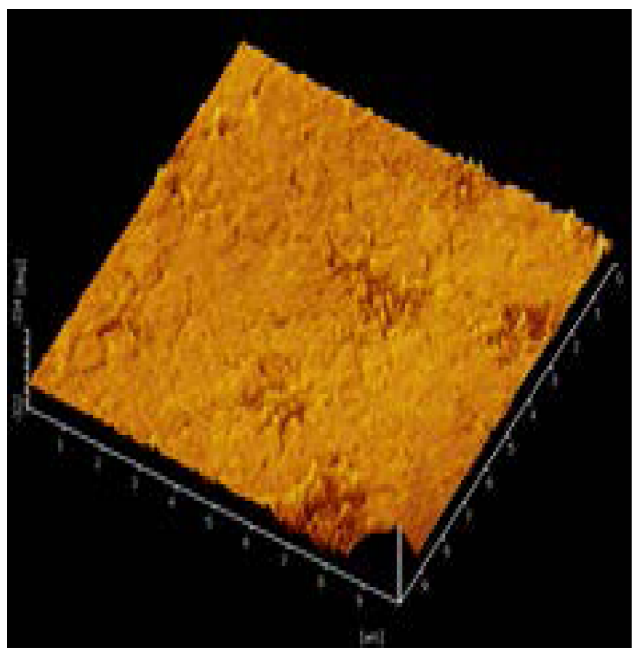

(a)

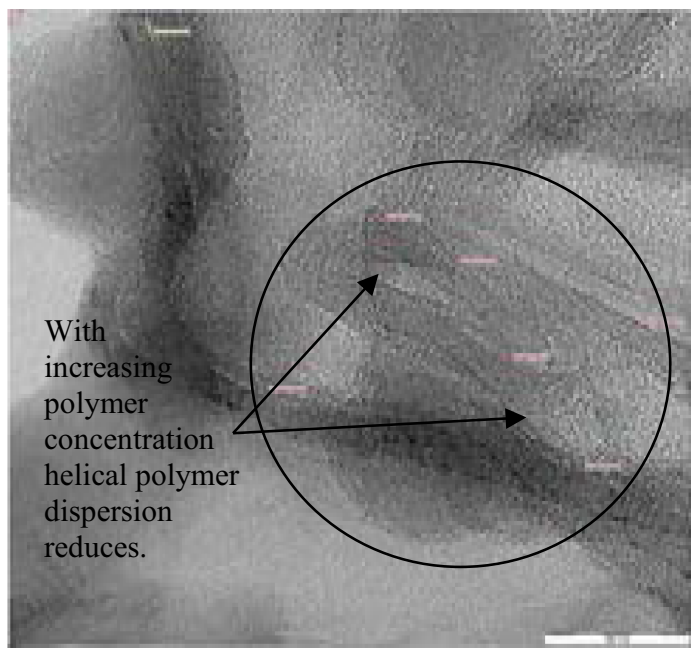

(b)

Fig. 5. 3\% PP PMB (a) AFM image (b) TEM image.

The morphological segregation can be better understood on the concept of solubility parameter which describe the interaction between the molecules on the basis of solubility parameter to predict the extent of mix ability when two different materials being mixed [2]. The colloidal stability of the mix depends on dispersive interaction between molecules due to the dispersive component, the polar component, and hydrogen component. Bitumen saturates has the solubility parameter between 17.4 and $20 \mathrm{MPa} 0.5$ [2] when mixed with polypropylene with solubility parameter between 16 and $19.2 \mathrm{MPa} 0.5$ [11] interact with bitumen saturate oils, initiate penetration of bitumen saturate oils into the polymer with the formation of swollen polymer particles within PMB blend. Thus even a small addition of polymer in the blend increases the viscosity of PP PMB [12] and induces the polymer phase in the blend which soon segregates upon cooling as observed by AFM scanned images (Figure 3-5). 


\subsection{Asphaltene content analysis (ASTM D 3279)}

ASTM n-heptane precipitation method was used to determine asphaltene content in virgin bitumen and PP modified bitumen. Asphaltene is the most difficult to define as till now it was noted by many researchers that it is very difficult to isolate them alone and still their chemical formula can't be established yet. Thus the only way to characterized them based on their insolubility in pentane or heptane [13]. The asphaltene content represented by an insoluble content in n-heptane is presented in Table 1. From previous research, it was found that the concentration of asphaltene usually varies from 5 to $25 \%$ in bitumen [14] which in turn depends on the origin of the oil crude source. Usually, asphaltene content in the range of between $5-25 \%$ is considered as moderate range, which exhibit sol-gel characteristics basically responsible for their viscoelastic properties [15]. The sol-gel characteristic of bitumen is considered beneficial as characterized by delay in the elastic deformability that will help in accommodating larger stresses in pavement because of the considerable degree of elastic deformation [16].From Table 1 it is inferred that aspahltene content for virgin bitumen was found to reduces gradually from $15 \%$ to $13.56 \%$ with the addition of polymer in bitumen. This decrease in asphaltene content indicates that the high molecular weight micelle becomes more peptized [16] or stabilized by the addition of polymer in the blend as observed by decrease in colloidal Index (CI), as presented in Table 1 enhancing the pseudo plastic behaviour of the blend which is very commonly observed for polymeric solution [17].

\subsection{Asphaltene content analysis (ASTM D 3279)}

The fractionate analysis of bitumen using SARA chromatography helps in understanding the chemistry of bitumen, where the analysed fractions namely saturates, aromatics, resins represent the maltenic fraction or oily stabilized base while asphaltene (n- heptane's insoluble) are dispersed in it. SARA is helpful in determining the stability of in term of Colloidal Index "Ic" defined as ratio of the dispersed phase to dispersing phase [15] where lower value of Ic represent that it would offer compatibility when blended with bitumen

$$
\text { Colloidal Index } I_{c}=\frac{\text { Asphaltene }+ \text { Saturates }}{\text { Resins }+ \text { Aromatics }}
$$

The results of SARA for virgin bitumen are shown in Table 1. From Table 1 it was observed that there is a decrease in asphaltene with the increase in resin by the addition of $\mathrm{PP}$ in the virgin bitumen. Bitumen with sufficient quantities of resins and aromatics shows adequate solvating power, where the asphaltenes are fully peptized, well dispersed and does not form extensive associations. Such bitumen's are known as solution of "SOL" type bitumen's [18]. When polymer is induced in such bitumen the higher molecular weight asphaltene with the similar molecular weight PP, would try to compete for solvency and thus absorb oils from maltene fraction (saturate $\&$ aromatics) and induces phase separation due to insufficient maltene being left in the blend.

From the SARA results, it can be inferred that composition of each fraction depends on the solubility parameter of the fraction to the particular solvent used. There is a decrease in asphaltene content observed in PP modified bitumen in comparison to virgin bitumen. One of the reasons for this decrease might because of the solvent, n-heptane which was used for asphaltene precipitation seems to be weaker as a solvent or the amount of solvent used for precipitation of asphaltene of PP PMB was not sufficient to completely precipitate the asphaltene. Thus the maltene solution obtained after separating asphaltene does contain a substantial portion of the asphaltene in maltene which was observed by the increase in resin content and decrease in aromatics for all PP PMB. Because of the polar nature of resin, it sticks together with asphaltene or may form chelate due to presence of heteroatoms in 
bitumen [19]. The increase in resin content was also due to the transition of asphaltene to resin during blending, which causes the enhancement in viscosities due to PP modification as mention in an earlier paper [12] causing agglomeration of suspended miscible polymer particles in the blend. The presence of saturates in bitumen are responsible for fluidity in the bitumen. A decrease in saturates and aromatics indicates that oily fraction of the bitumen was absorbed by the addition of polymer. The decrease in aromatics in PP PMB also indicates the formation of dispersed polymer in the blend as observed by the decrease in colloidal index and segregation of polymer phase as observed in all AFM scanned images (Fig. 3 - 5). Decrease in aromatics also indicates the oxidation at mixing by the formation of the carbonyl group as mentioned in earlier work [20].

Table 1. SARA analysis results.

\begin{tabular}{|c|c|c|c|c|c|}
\hline & $\begin{array}{c}\text { Asphaltene } \\
\mathbf{\%}\end{array}$ & $\begin{array}{c}\text { Saturates } \\
\mathbf{\%}\end{array}$ & $\begin{array}{c}\text { Aromatics } \\
\mathbf{\%}\end{array}$ & $\begin{array}{c}\text { Resins } \\
\mathbf{\%}\end{array}$ & CI \\
\hline $\begin{array}{c}\text { Virgin } \\
\text { Bitumen }\end{array}$ & 15 & 12 & 41 & 31 & 0.38 \\
\hline 1\% PP PMB & 11.05 & 6.77 & 39.63 & 41.53 & 0.22 \\
\hline 2\% PP PMB & 12 & 7.52 & 35.20 & 43.50 & 0.33 \\
\hline 3\% PP PMB & 13.56 & 8.09 & 31.78 & 46.10 & 0.28 \\
\hline
\end{tabular}

\subsection{Mechanical analysis of bituminous mix}

Dynamic creep test was conducted on triplicate samples prepared at optimum bitumen content obtained by Marshall Test results for control and PP modified samples [21]. The results are presented in the form of permanent accumulated strain and creep stiffness. The average mix stiffness modulus $\left(\mathrm{S}_{\mathrm{mix}}\right)$ obtained from the creep modulus of three prepared mix specimen at optimum binder content for particular bituminous mix is plotted in double logarithmic scale against stiffness modulus of bituminous binder $\left(\mathrm{S}_{\mathrm{bit}}\right)$, evaluated by using Van der Poel's nomograph as shown in Figure 6. The resistances to permanent deformation from the creep tests can be observed from the slope of the line of the log-log relationship of mixture stiffness versus binder stiffness. The slope of the line for each particular mix indicates sensitivity of the mix to loading time and hence bitumen stiffness [22].

A comparison of the mix stiffness with control mix at start and end of 1 hour test is presented in Table 2. When compared to control mix it was observed that there was an increase of $83 \%$ and $71 \%$ in creep stiffness for $1 \% \mathrm{PP}$ and $2 \%$ PP respectively. $3 \% \mathrm{PP}$ modified samples failed to show any improved performance as presented in Table 2. The higher percentage of polymer in blend although does enhances the viscosity but the agglomeration of polymer particles failed to coat the aggregate surface properly, thus unable to increase the modified bituminous concrete mix stiffness. The phase separated layer for $1 \%$ PP PMB as observed in AFM image (Figure.3) shows a higher surface roughness consisting of two different microstructure provides a better coating to the aggregate particle and enhanced viscoelastic property of binder. The combined effect of it is increased in stiffness value as observed by dynamic creep results for $1 \% \& 2 \%$ PP PMB tested samples. 
Table 2. Mix stiffness at the start and end of the test.

\begin{tabular}{|c|c|c|c|}
\hline Mix Type & $\begin{array}{c}\text { Stiffness at Start } \\
\text { (MPa) }\end{array}$ & $\begin{array}{c}\text { Stiffness at } \\
\text { End(MPa) }\end{array}$ & $\begin{array}{c}\text { Increase } \uparrow / \text { Decrease } \downarrow \\
\text { in Stiffness at End } \\
\text { w.r.t Control mix (\%) }\end{array}$ \\
\hline Control Mix & 192.05 & 18.98 & \\
\hline $1 \%$ PP PMB & 788.88 & 111.06 & $82.91 \uparrow$ \\
\hline $2 \%$ PP PMB & 822.7 & 66.02 & $71.25 \uparrow$ \\
\hline $3 \%$ PP PMB & 212.3 & 29.89 & $36.50 \uparrow$ \\
\hline
\end{tabular}

\section{Mix Stiffness Vs Bitumen Stiffness}

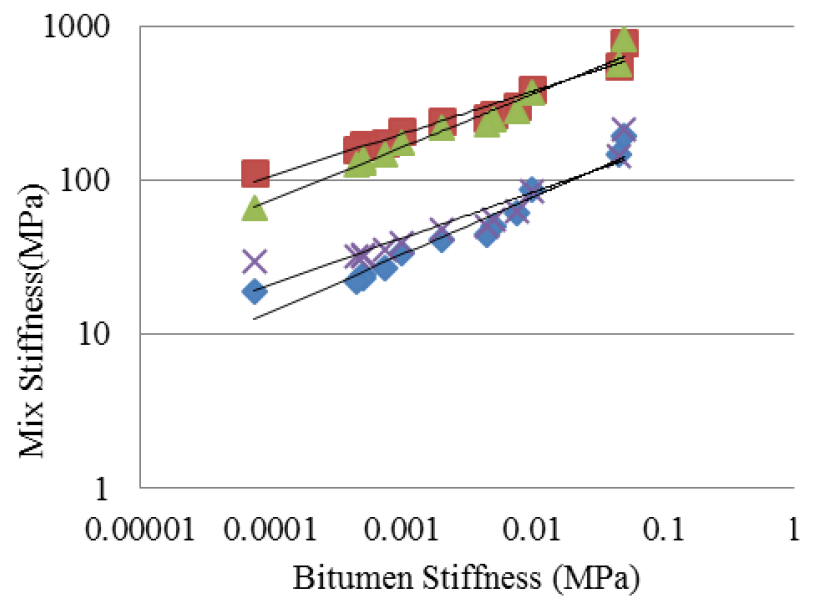

\section{- Stiff of \\ V.Bit}

Stiff of $1 \%$

PP PMB

Stiff of $2 \%$

PP PMB

$\times$ Stiff of $3 \%$

PP PMB

Fig. 6. Mix stiffness vs bitumen stiffness.

Results of the dynamic creep test can also be used to estimate strain accumulation in the sample against repeated loading cycles. The strain rate can effectively represent the viscoelastic behaviour of bituminous materials under repetitive loading cycle [23]. From Figure 7, it is observed that first 100 cycles are considered as compaction zone followed by a stable zone where stress is directly proportional to strain or can be defined as linear zone, where material show resistance to permanent deformation.

The stress-strain relationship in bituminous material can also be studied in view of dissipated energy concept [24] where, work done on the pavement by each application of the wheel load. During application of the wheel load a certain part of the work done is utilized in deforming the surface layer of the pavement. From Figure 7 it is observed that $2 \%$ PP \& $3 \%$ PP modified bituminous mixtures showed higher strain level till the end in comparison to $1 \% \mathrm{PP}$ and virgin bitumen. 


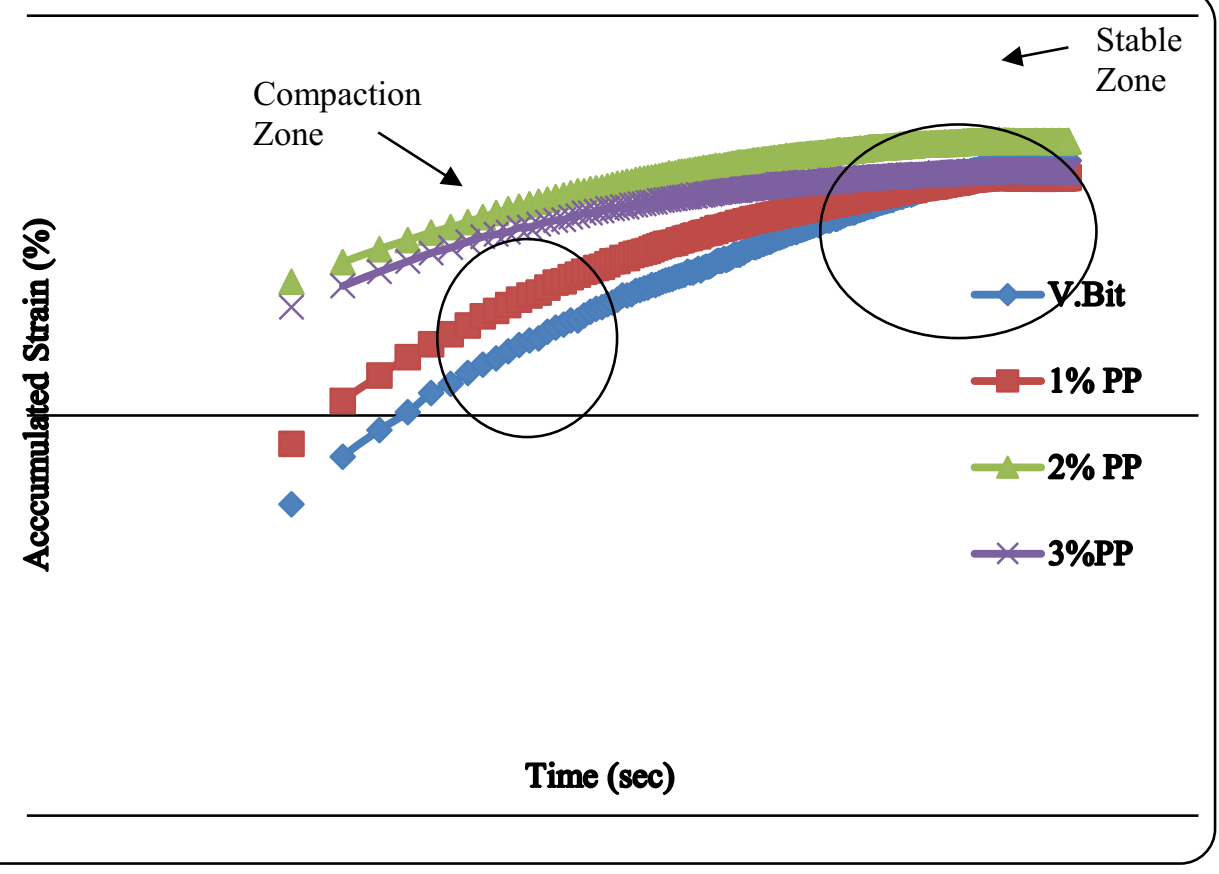

Fig. 7. Log accumulated strain vs log time of loading.

This was due to the viscoelastic behaviour, which is considered to be major component as some part of the dissipated energy was recovered during elastic recovery of the binder where polymer entangled chain realign themselves to resist the deformation of the pavement while the rest of the energy is released as crack initiation followed by plastic deformation of the material [23].It can be concluded that 2\% \& 3\% PP PMB mixtures dissipate higher energy than control mix which may be considered due to stiffening effect of the polymer, because of its dispersion ability in blend forming the three dimensional network which was being proved by the significant effect on material behaviour to deformation and also to the strain level achieved till the end of test

\section{Conclusion}

The phase separated polymer layer for all percentages of polymer in the blend is considered as beneficial as it enhances material stiffness as observed by the dynamic creep results.

The chemical analysis of blend revealed that asphaltene are not only responsible for inducing the stiffening effect in the blend but the phase separated polymer layer as observed by AFM scanned images with lower colloidal index considered responsible for enhanced mechanical properties of polypropylene modified bituminous mix. The TEM images revealed the well-defined polymer network represented by lamella in all scanned images are mainly responsible for enhanced mechanical properties of modified bituminous mix.

It is concluded that modification of bitumen will help in improving the deformation behaviour of the bituminous mix when the concentration of the polymer in the blend is kept below $3 \%$. 


\section{References}

1. W. Uddin, Appl. Rheo, 13, 191-199 (2003)

2. P.G. Redelius, Fuel, 79, 27-35 (2000)

3. C. Giavarini, et al., Fuel, 75, 681-686 (1996)

4. L. Michon, D Martin, JP Planche, B Hanquet, Fuel, 76, 9-15 (1997)

5. D. Sybilski, Mat and Struct, 30,182-187 (1997)

6. L. Didier, Advances in Colloid and Interface Sci, 145, 42-82(2009)

7. B. Stuart, Polymer Analysis. United Kingdom: John Wiley \& Sons, Ltd (2002)

8. Loeber, et al., J. Micro, 182, 32-39 (1996)

9. S.P. Wu, et al., Const. Build. Mat., 23,1005-1010 (2009)

10. E. R. Dourado, et al., J. Micro., 245,119-128 (2012)

11. A. S. Michaels, et al., J. Appl. Poly. Sci. 12, 1621-1624 (1968)

12. I. Kamaruddin. N.Z. Habib, M. Napiah and I. M. Tan, Int. J. Civil and Envi. Eng., 3, 96100 (2011)

13. R. R. Coelho, et al., Fuel Proces. Tech., 87, 325-333 (2006)

14. D. W. John Read, The Shell Bitumen Handbook, Fifth ed.: Thomas Telford Publishing, (2003)

15. S. Haddadi, et al., Const. Build. Mat., 22, 1212-1219 (2008)

16. L. Loeber, et al., Fuel, 77, 1443-1450 (1998)

17. S. N. Bhattacharya, "Rheology Fundamentals and Measurement," R. M. I. o. T. M. Australia., Ed., ed. Melbourne: Royal Melbourne Institute of Technology (1997)

18. GD Airey, TM Singleton, AC Collop, J. Mat in Civil Eng., 14, 344-354 (2002)

19. J. F. Masson, et al., J. of Micro. 221, 17-29 (2006)

20. N. Z. Habib, et al., National Postgraduate Conference (NPC), 1-7 (2011)

21. I. Kamaruddin, N. Z. Habib, M. Napiah and I. M. Tan, World Acad. Sci. Eng. and Tech., 58, 830 - 835 (2011)

22. I. Kamruddin, $P h D$ Thesis, Civil Engineering Department, University of Leeds (1998)

23. I. Widyatmoko, et al., Materials and Structures, vol. 32, pp. 304-310, 1999

24. I. Widyatmoko, C. Ellis, J. M. Read, Mat.and Struct., 32, 218-223 (1999) 